\title{
Cerebellar Roles in Self-Timing for Sub- and Supra-Second Intervals
}

\author{
Shogo Ohmae, ${ }^{1,2}$ Jun Kunimatsu, ${ }^{1,3}$ and Masaki Tanaka ${ }^{1}$ \\ ${ }^{1}$ Department of Physiology, Hokkaido University School of Medicine, Sapporo 060-8638, Japan, ${ }^{2}$ Department of Neuroscience, Baylor College of Medicine, \\ Houston, Texas 77030, and ${ }^{3}$ Laboratory of Sensorimotor Research, National Eye Institute, National Institutes of Health, Bethesda, Maryland 20892
}

Previous studies suggest that the cerebellum and basal ganglia are involved in sub-second and supra-second timing, respectively. To test this hypothesis at the cellular level, we examined the activity of single neurons in the cerebellar dentate nucleus in monkeys performing the oculomotor version of the self-timing task. Animals were trained to report the passage of time of 400, 600, 1200, or 2400 ms following a visual cue by making self-initiated memory-guided saccades. We found a sizeable preparatory neuronal activity before self-timed saccades across delay intervals, while the time course of activity correlated with the trial-by-trial variation of saccade latency in different ways depending on the length of the delay intervals. For the shorter delay intervals, the ramping up of neuronal firing rate started just after the visual cue and the rate of rise of neuronal activity correlated with saccade timing. In contrast, for the longest delay ( $2400 \mathrm{~ms})$, the preparatory activity started late during the delay period, and its onset time correlated with self-timed saccade latency. Because electrical microstimulation applied to the recording sites during saccade preparation advanced self-timed but not reactive saccades, regardless of their directions, the signals in the cerebellum may have a causal role in self-timing. We suggest that the cerebellum may regulate timing in both sub-second and supra-second ranges, although its relative contribution might be greater for sub-second than for supra-second time intervals.

Key words: cognitive function; extracellular recording; internal time; oculomotor; primate; time reproduction

\section{Significance Statement}

How we decide the timing of self-initiated movement is a fundamental question. According to the prevailing hypothesis, the cerebellum plays a role in monitoring sub-second timing, whereas the basal ganglia are important for supra-second timing. To verify this, we explored neuronal signals in the monkey cerebellum while animals reported the passage of time in the range $400-2400 \mathrm{~ms}$ by making eye movements. Contrary to our expectations, we found that neurons in the cerebellar dentate nucleus exhibited a similar preparatory activity for both sub-second and supra-second intervals, and that electrical simulation advanced self-timed saccades in both conditions. We suggest that the cerebellum plays a causal role in the fine adjustment of self-timing in a larger time range than previously thought.

\section{Introduction}

The role of the cerebellum in movement timing is well established. The cerebellum coordinates the timing of multiple muscle

Received July 12, 2016; revised Feb. 16, 2017; accepted Feb. 18, 2017.

Author contributions: S.0. and M.T. designed research; S.0. performed research; S.0. and J.K. analyzed data; S.O. and M.T. wrote the paper.

This work was supported by the grants from the Ministry of Education, Culture, Sports, Science and Technology of Japan; the Ministry of Health, Labour and Welfare of Japan; the Takeda Science Foundation; the Japan Society for the Promotion of Science (Grant-in-Aid for JSPS Fellows, S.0.); and the Uehara Memorial Foundation (S.0.). One animal was provided by the National Bio-resource project. We are grateful to K. Ohmae for editing illustrations, M. Suzuki for administrative help, M. Takei and Y. Hirata for manufacturing some equipment, and all lab members for comments and discussions.

The authors declare no competing financial interests.

Correspondence should be addressed to Shogo Ohmae or Masaki Tanaka, Department of Physiology, Hokkaido University School of Medicine, North 15, West 7, Sapporo 060-8638, Japan. E-mail: shogo.ohmae@bcm.edu or masaki@med.hokudai.ac.jp. contractions for accurate movements in the range of tens of milliseconds (Vilis and Hore, 1980; Robinson et al., 1993; Thier et al., 2000), and regulates the timing of discrete rhythmic movements in the range of hundreds of milliseconds (Thach et al., 1992; Spencer et al., 2003; Schaal et al., 2004; Thaut et al., 2008). Other studies also suggest that the lateral part of the cerebellum plays a role in adjusting the timing of self-initiated, predictive movements (Ivry and Keele, 1989; Xu et al., 2006; Bares et al., 2007). This part of the cerebellum is anatomically connected with the motor cortices via the thalamus (Dum and Strick, 2003; Strick et al., 2009) and appears to be involved in the generation of slow cortical potential preceding self-initiated movements (Sasaki et al., 1979; Ikeda et al., 1994). Recent evidence also indicates a role 
for the lateral cerebellum in nonmotor temporal processing for the prediction of future events (Xu et al., 2006; O’Reilly et al., 2008; Ohmae et al., 2013) as well as alteration of temporal prediction of sensory events through learning (Roth et al., 2013).

While the cerebellum is involved in temporal processing, its operational range appears to be limited mostly to sub-second intervals (for review, see Lewis and Miall, 2003a; Ivry and Spencer, 2004). For example, rabbits can generate cerebellum-dependent, temporally accurate predictive eye blinks in response to conditioned auditory stimuli that last for several hundred milliseconds, but not to those last for $>1.5 \mathrm{~s}$ (Medina and Mauk, 2000). In addition, recent functional imaging studies have shown that the cerebellum is activated by tasks requiring temporal processing in sub-second but not supra-second ranges, while the basal ganglia exhibit greater activation for suprasecond compared with sub-second timings (Rao et al., 2001; Lewis and Miall, 2003b; Harrington et al., 2004; for review, see Buhusi and Meck, 2005; Merchant et al., 2013). These observations led to the hypothesis that the cerebellum only plays a role in sub-second timing, while the basal ganglia participate in supra-second temporal processing.

To test this hypothesis, we examined the activity of single neurons in the cerebellar dentate nucleus in monkeys performing the oculomotor version of the time production task (Tanaka, 2006). In our self-timed saccade paradigm, the animals made a self-initiated saccade following the mandatory delay interval that ranged from 400 to $2400 \mathrm{~ms}$. Consistent with a previous study (Ashmore and Sommer, 2013), many neurons in the posterior part of the dentate nucleus exhibited a gradual ramp-up of firing rate before self-timed saccades. Unexpectedly, however, the magnitude of neuronal activity was comparable between trials with sub-second and supra-second delay intervals, and the ramping up of activity consistently started $\sim 500 \mathrm{~ms}$ before selfinitiated saccades. Further analysis showed that trial-by-trial variation of saccade latency correlated with the time course of neuronal activity in different ways between sub-second and supra-second timings. Based on these observations, we suggest that signals in the lateral cerebellum play a role in the fine adjustment of saccade timing for different time ranges.

\section{Materials and Methods}

Two female Japanese monkeys (Macaca fuscata; Q and P; 4.2 and $5.2 \mathrm{~kg}$, respectively) were used. All experimental protocols were approved in advance by the Hokkaido University Animal Care and Use Committee. The procedures for animal surgery and recording experiments were identical to those described previously (Tanaka, 2005; Ohmae et al., 2013).

Animal preparation. In separate surgeries under general isoflurane anesthesia, a pair of plastic head holders was fixed to the skull and an eye coil was implanted under the conjunctiva. Analgesics were administered during each surgery and for the following few days. After recovery from surgery, the monkeys were trained in the oculomotor tasks for 3-6 months until they correctly performed the tasks in $>90 \%$ of trials. Dur- ing the training and the subsequent experimental sessions, the monkey's head was secured to the primate chair in a darkened booth, and horizontal and vertical eye position signals were recorded using the search coil technique. After training on eye movement tasks, a third surgery was undertaken to place a recording cylinder for vertical electrode penetration aimed at the deep cerebellar nuclei. The location of the cylinder was verified using magnetic resonance images. Daily recording sessions began after full recovery from the surgery. Antibiotics were administered during the course of the experiments as necessary.

Stimuli and behavioral task. Visual stimuli were presented on a 24 inch cathode-ray tube monitor (refresh rate, $60 \mathrm{~Hz}$ ) that was located $38 \mathrm{~cm}$ away from the eyes and subtended $64 \times 44^{\circ}$ of visual angle. Four different visual stimuli were used. The fixation point (FP; green or red) and saccade target (white) were $0.5^{\circ}$ squares. Audiovisual feedback for the selftimed task was a red $2^{\circ}$ square and a brief tone ( $2 \mathrm{kHz}$ square wave, $50 \mathrm{~ms}$ ) presented through a speaker placed in the experimental booth. Throughout the experiments, the size of the eye position window was $2^{\circ}$ for initial fixation and $3^{\circ}$ for the saccade target. Correct performance was reinforced with drops of apple juice. The behavioral task and data acquisition were controlled by a Windows-based real-time data acquisition system (TEMPO; Reflective Computing) running on laboratory PCs.

We used two saccade paradigms with different FP color (Fig. 1A). In the conventional memory-guided saccade task (Hikosaka and Wurtz, 1983), a visual cue was presented briefly $(200 \mathrm{~ms})$ either $16^{\circ}$ left or right of the FP during central fixation. Monkeys were required to remember the cue location and maintain fixation for an additional delay interval of 400, 600, 1200, or $2400 \mathrm{~ms}$. For one animal (monkey Q), the shortest delay interval (400 ms) was not presented during the early recording sessions $(n=35$ neurons). The delay interval was chosen randomly for each trial, so that the animals were unable to predict the end of the delay interval. Monkeys were 
A

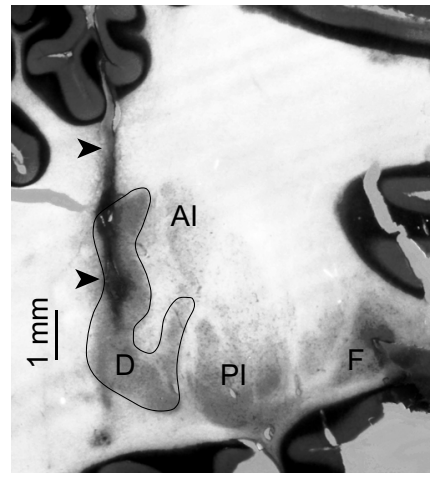

B

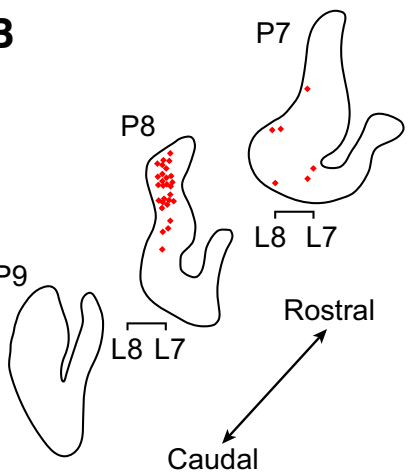

Figure 2. Recording sites of monkey P. A, A photograph of a coronal section at the level $8 \mathrm{~mm}$ posterior to the interaural line (P8). The track of 30 gauge injection cannula, which was inserted after all recording sessions, is visible at P8L7 (arrowheads). Most neurons were recorded from the penetration at the track location. D, Dentate nucleus; $\mathrm{Al}$, anterior interpositus nucleus; $\mathrm{PI}$, posterior interpositus nucleus; $F$, fastigial nucleus. $\boldsymbol{B}$, Locations of task-related neurons. Some data points (red dots) are horizontally jittered for presentation. The brackets indicate the lateral position relative to the midline (L7-L8).

A

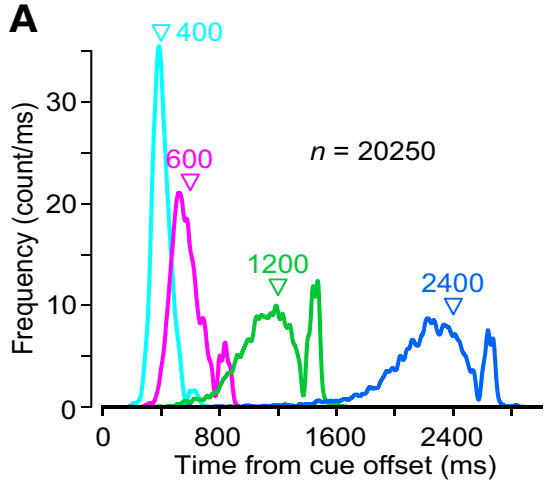

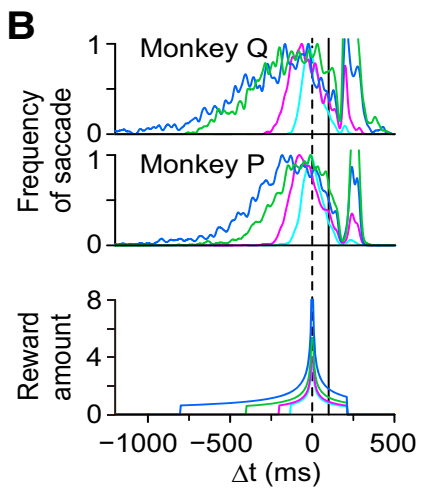

Figure 3. Behavioral data. $\boldsymbol{A}$, Latency distribution of self-timed saccades for 62 recording sessions in two monkeys. Different colors represent the data for different mandatory intervals, which are indicated by inverted triangles. $\boldsymbol{B}$, Distribution of saccade timing relative to the end of the mandatory delay interval $(\Delta t)$ for each monkey. Timing of the audiovisual feedback is indicated by a solid vertical line ( $100 \mathrm{~ms}$ following the mandatory delay). The bottom panel plots the amount of reward relative to that in the conventional memory saccade task as a function of $\Delta t$.

required to make a saccade to the cue location within $400 \mathrm{~ms}$ after the FP offset to obtain reward. The visual cue reappeared $400 \mathrm{~ms}$ after the FP offset for confirmation. Thus, in this task, the time of the saccade was explicitly instructed by the FP offset and the animal did not need to monitor the passage of time following the cue.

In the self-timed memory saccade task (Tanaka, 2006, 2007; Kunimatsu and Tanaka, 2012; Ashmore and Sommer, 2013), animals were required to make a self-initiated saccade to the location of a previously presented visual cue without any immediate external trigger. The FP disappeared only after the animals generated a self-timed saccade, when eye position deviated $>3^{\circ}$ from the FP. The visual cue reappeared $200 \mathrm{~ms}$ after the FP offset. The mandatory delay interval following the cue offset was selected from 400, 600, 1200, or $2400 \mathrm{~ms}$. In each trial, no explicit information about the length of the delay period was provided in advance of the visual cue. Instead, the mandatory delay interval was fixed during 10 successive trials and was sequentially increased every 10 trials from 400 to $2400 \mathrm{~ms}$ (Fig. 1C). After completion of 40 self-timed saccade trials, eight conventional memory saccade trials with different delay intervals (see above) were presented in a pseudorandom order. The rightward and leftward saccade trials were alternated for the self-timed saccade trials but were intermingled randomly for the conventional memory saccade trials (Fig. $1 C$, red and blue arrows). To inform monkeys of the delay interval, audiovisual feedback $\left(50 \mathrm{~ms}\right.$, red $2^{\circ}$ square and $2 \mathrm{kHz}$ tone) was presented $100 \mathrm{~ms}$ after the end of the mandatory delay period in every self-timed saccade trial, regardless of the animal's behavior (Fig. 1B). The location of visual feedback was either at the FP or the cue location, depending on eye position at the time of stimulus appearance.
In each trial, the animals were rewarded for a saccade that was generated later than two-thirds of the mandatory delay interval and earlier than 110 ms following the audiovisual feedback. For example, the times of rewarded saccades ranged from 400 to $810 \mathrm{~ms}$ following the cue offset in trials with a $600 \mathrm{~ms}$ mandatory delay interval. In addition, to reinforce temporally accurate responses, the amount of reward varied according to saccade timing relative to the mandatory delay interval such that

$R_{\text {self }}= \begin{cases}R_{\text {conv }} \times(1+1 / \sqrt{|\Delta t|}) & \text { if }(1+1 / \sqrt{|\Delta t|})<8, \\ R_{\text {conv }} \times 8 & \text { otherwise, }\end{cases}$

where $R_{\text {self }}$ and $R_{\text {conv }}$ are the amounts of reward for the self-timed trial and the conventional memory saccade trial, respectively, and $\Delta t$ indicates the difference in time (in milliseconds) between the self-timed saccade and the end of the mandatory delay interval (Fig. $2 B$, bottom). The amount of reward in each trial was controlled by the open duration of the solenoid valve. Saccades later than $110 \mathrm{~ms}$ from the feedback were assumed to be generated in response to the feedback and were not rewarded. When a saccade was generated before the feedback, the reward was given $100 \mathrm{~ms}$ after the end of the audiovisual feedback; otherwise, the reward delivery was further delayed until $350 \mathrm{~ms}$ after the termination of the saccade.

Recording procedures. Single neuron recordings were undertaken in two dentate nuclei of two monkeys. Tungsten microelectrodes $(\sim 1.0 \mathrm{M} \Omega$ at $1 \mathrm{kHz}$, Alpha Omega Engineering) were lowered through a 23 gauge stainless tube guided by a grid system (Crist Instruments). The electrodes were advanced using a micromanipulator (MO97S, Narishige) attached to the recording cylinder. Signals obtained from the electrodes were amplified, filtered, and monitored online using oscilloscopes and an audio device. Once a taskrelated neuron was encountered, waveforms of action potentials were isolated using software with real-time template matching algorithms (Multi Spike Detector, MSD, Alpha Omega Engineering). The occurrence of each action potential during experiments was saved in files as a time stamp with the data of eye movements and visual stimuli. Each neuron was recorded for 5-20 blocks of trials (i.e., 240-960 trials). The task-related neurons were found in the caudal part of the cerebellar dentate nucleus. The best coordinates for electrode penetration were centered at the location $7 \mathrm{~mm}$ posterior to the ear canals and $7 \mathrm{~mm}$ left from the midline (P7L7) for monkey $\mathrm{Q}$ and at the location $8 \mathrm{~mm}$ posterior and $7 \mathrm{~mm}$ left (P8L7) for monkey $\mathrm{P}$ (Fig. 2), respectively.

Electrical microstimulation. To examine a causal role of neuronal activity, electrical stimulation was delivered to the recording sites through lowimpedance $(<800 \mathrm{k} \Omega$ at $1 \mathrm{kHz})$ electrodes. A train of $0.2 \mathrm{~ms}$ biphasic pulses at $333 \mathrm{~Hz}$ for $200 \mathrm{~ms}$ was delivered as electrical stimulation. The intensity of current was monitored by measuring the voltage across a $1 \mathrm{k} \Omega$ resistor placed in series with the electrode, and was adjusted to $100 \mu \mathrm{A}$. In the selftimed memory saccade task, the train of stimulation pulses terminated at $350-400,520-600,1000-1150$, and 2000-2300 ms following the cue offset for trials with the mandatory delay intervals of 400, 600, 1200, and $2400 \mathrm{~ms}$, respectively. Stimulation timing was determined based on the distribution of saccade latency in trials without stimulation (Fig. 3) so that electrical stimulation was delivered before most of the self-timed saccades. When saccades occurred earlier than electrical microstimulation, the trials were removed from the analysis. In the conventional memory saccade task, electrical stimulation was delivered at the same time as in the self-timed task (delay period) or at the time of FP offset (response period). 
Data acquisition and analysis. Eye position signals were obtained directly from the eye coil device (MEL-25; Enzanshi Kogyo). Data were digitized, sampled at $1 \mathrm{kHz}$, and stored in files during the experiments for further off-line analysis using Matlab (Mathworks). For behavioral analysis, the distribution of self-timed saccade latency was obtained by convolving the millisecond-by-millisecond occurrence of saccades with Gaussians ( $\sigma=10 \mathrm{~ms}$; Fig. 3). To exclude the data during the transition of mandatory delay intervals, the first two trials in each subblock were removed from all quantitative analyses. The medians of saccade latency in the third trial in each subblock averaged $372 \pm 32$ ms (mean $\pm \mathrm{SD}, n=62$ recording sessions), $511 \pm 53 \mathrm{~ms}, 1030 \pm 147 \mathrm{~ms}$, and $2163 \pm 182 \mathrm{~ms}$ for the mandatory delays of $400,600,1200$, and $2400 \mathrm{~ms}$, respectively. For the analysis of stimulation experiments, the distribution of saccade latency was smoothed by a Gaussian filter ( $\sigma=20 \mathrm{~ms}$ ) only for the purposes of presentation (see Fig. 10B).

To reveal the time courses of neuronal activity, spike density profiles (Gaussian, $\sigma=20$ $\mathrm{ms}$ ) were computed; however, unless noted otherwise, all quantitative measures were based on the spike counts at specific time windows in each condition. Baseline activity was measured in a $500 \mathrm{~ms}$ fixation interval before the cue onset. To quantify firing modulation before selftimed saccades, firing rate was measured in a $100 \mathrm{~ms}$ period starting $150 \mathrm{~ms}$ before saccades. Neurons with a ramp-up of activity during saccade preparation ( $n=66)$ were analyzed separately from those with a ramp-down of activity $(n=26$; see Fig. 6). For analysis of the preparatory activity, the data for individual trials were aligned with saccade initiation rather than with cue offset, because the trial-by-trial variation of saccade timing might result in an underestimation of firing rate just before saccades if the data were aligned with the cue offset (Fig. 4, left). For display purposes, the traces of spike density were shifted in time so that the data were aligned with the mean saccade latency measured from the cue offset (see Figs. 7, $8 A$ ). To evaluate the time courses of preparatory activity, the slope of simple linear regression (least squares) was computed for the means of firing rates measured during six consecutive $50 \mathrm{~ms}$ intervals (four intervals for the $400 \mathrm{~ms}$ condition) ending at $50 \mathrm{~ms}$ before self-timed saccades (see Fig. 9). For comparison, we also evaluated the rate of rise of neuronal activity by fitting a nonlinear function with parameters of the baseline, onset time, and slope of ramping activity using least squares (Tanaka, 2007, their Fig. 5). Details of other quantitative measures and associated statistical tests are described in the relevant text in Results.

Histological procedures. Following the end of experiments, monkey $\mathrm{P}$ was deeply anesthetized, and the brain was removed, fixed, and equilibrated with $30 \%$ sucrose. Histological sections (100 $\mu \mathrm{m}$, coronal) were cut and stained with cresyl violet. The recording sites were reconstructed according to the stereotaxic coordinates, and the depth of electrode tip relative to the dorsal border of the dentate nucleus that was verified physiologically during experiments.

\section{Results}

\section{Oculomotor performance during recording sessions}

During recording sessions, both monkeys performed the tasks very well; the proportion of rewarded trials in the self-timed tasks
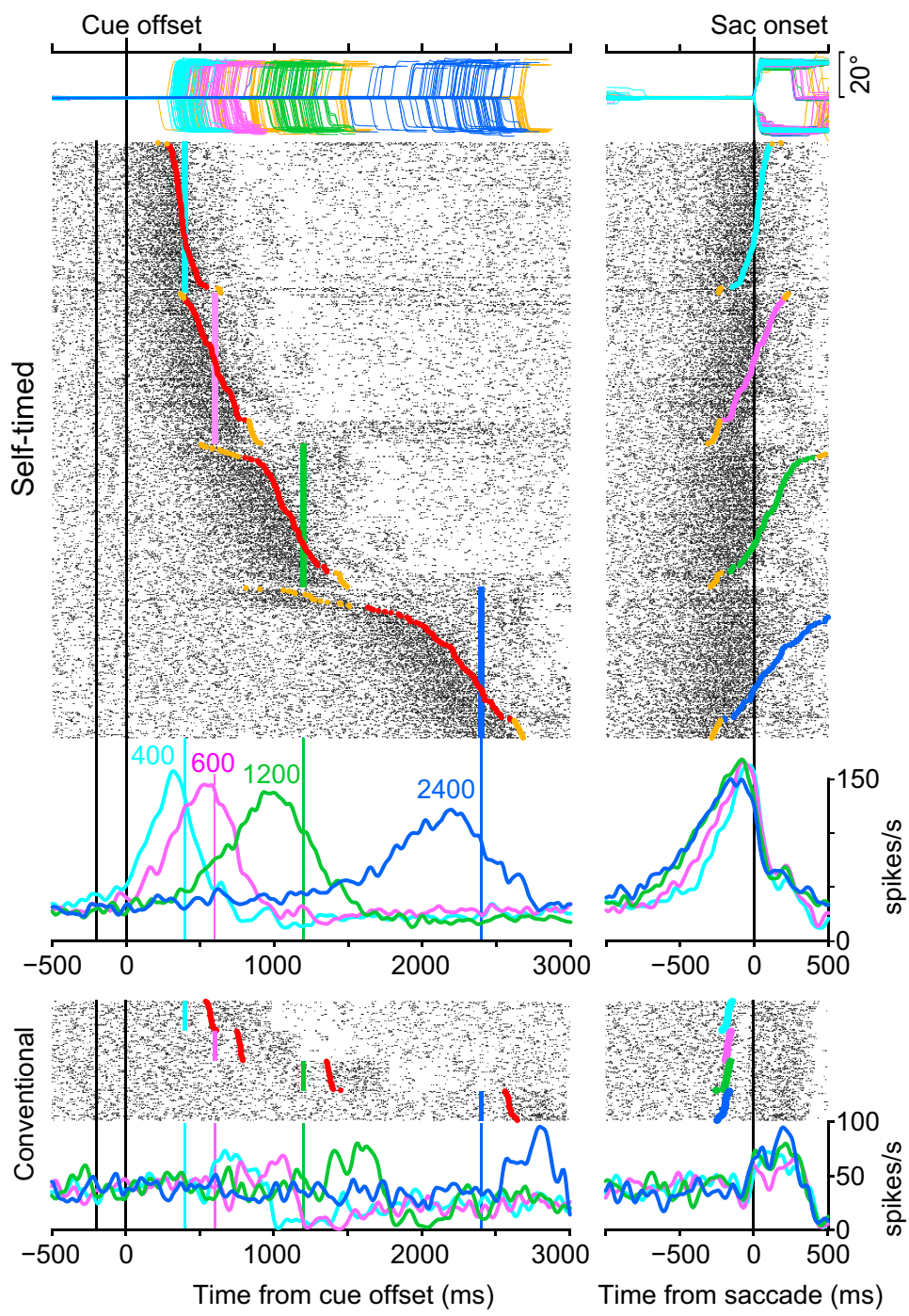

Figure 4. Neuronal activity of a representative neuron during the two saccade paradigms. Eye position traces and spike data during the self-timed task (top panels) and the conventional memory saccade task (bottom panels) are shown. Data are aligned with either the cue offset (left) or saccade initiation (right). Trials are sorted according to saccade latency for each condition. Times onset, cue offset, saccade initiation, and the end of mandatory delay interval are overlaid on the raster plot. Different uting the spike density. Note the absence of ramp-up of neuronal activity in the conventional memory saccade trials, which are presented in a block containing different delay intervals (see Materials and Methods; Fig. 10).

averaged $99 \pm 6 \%(\mathrm{SD}), 98 \pm 2 \%, 96 \pm 4 \%$, and $93 \pm 5 \%$ for the mandatory delay intervals of 400, 600, 1200, and $2400 \mathrm{~ms}$, respectively. The distributions of saccade latency were bimodal for all but the shortest mandatory delay interval. The first peak occurred around the end of the mandatory delay period (Fig. $3 A$, inverted triangles), indicating that the animals were able to adjust saccade timing for different intervals. When we replotted the data relative to the end of the mandatory interval ( $\Delta t$; Fig. $3 B$, top panels), the second peak occurred around $250 \mathrm{~ms}$, indicating that the animals made reactive saccades in response to the feedback that was presented $100 \mathrm{~ms}$ after the mandatory interval (vertical solid line). Because we were interested in self-timed behavior in the task, data for the trials with $\Delta t>210$ ms were removed from further quantitative analyses ( $9.8 \%$ of all trials). These reactive saccades in the self-timed task were not rewarded during experiments (see Materials and Methods; Fig. 3B, bottom).

In the conventional memory saccade task, reaction time measured from the FP offset averaged $170 \pm 23 \mathrm{~ms}(\mathrm{SD}), 173 \pm 22$ 

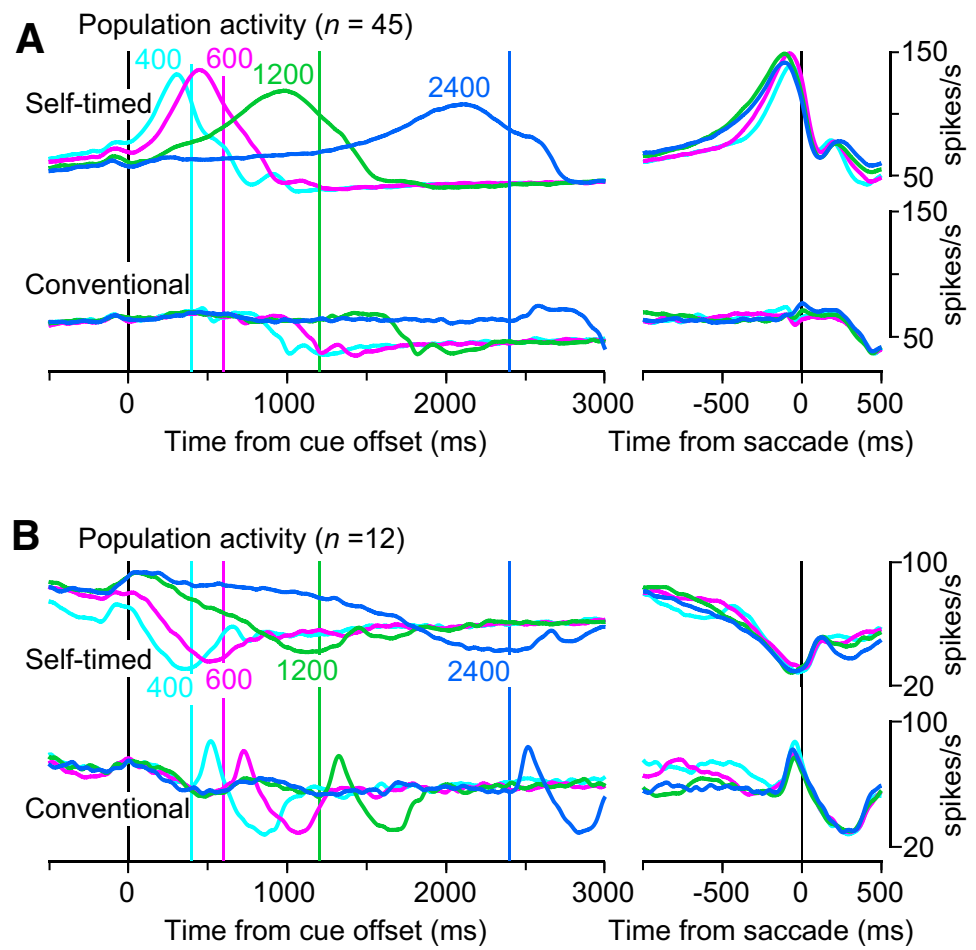

Figure 5. Time courses of the population activity. $A$, Population activity for 45 neurons that exhibited a ramp-up of firing rate during the self-timed task. $\boldsymbol{B}$, Population activity for 12 neurons that exhibited a ramp-down of firing rate. Note that the ramp-up neurons showed no firing modulation around the time of saccades in the conventional memory saccade task $(\boldsymbol{A})$, while the ramp-down neurons exhibited a transient activity $(\boldsymbol{B})$.

$\mathrm{ms}, 178 \pm 23 \mathrm{~ms}$, and $183 \pm 26 \mathrm{~ms}$ for trials with delay intervals of $400,600,1200$, and $2400 \mathrm{~ms}$, respectively. The proportions of error trials with early saccades before the FP offset were $0 \pm 0 \%$ (mean $\pm \mathrm{SD}$ ), $0 \pm 0 \%, 1.1 \pm 2.9 \%$, and $3.1 \pm 4.8 \%$ for the delays of $400,600,1200$, and $2400 \mathrm{~ms}$, respectively, indicating that monkeys were well trained to make a saccade in response to the FP offset.

\section{Basic characteristics of preparatory activity for self-timing}

A total of 92 task-related single neurons were recorded from two dentate nuclei (Fig. 2) of two monkeys ( $n=40$ for monkey P and 52 for monkey Q). Figure 4 illustrates a representative neuron that exhibited a ramp-up of activity before self-timed saccades in both directions. This neuron showed virtually no visual response to the cue and displayed preparatory activity for all mandatory delay intervals, but the firing modulation started later for longer delay intervals (left). When the same data were realigned with saccade initiation (right), the rate of rise of neuronal activity was similar across different mandatory delay intervals, while a slight prelude of activity was evident in trials with longer delay intervals. For trials with supra-second mandatory delay intervals (green and blue traces), the preparatory activity for self-timed saccades was found only during the last $\sim 700 \mathrm{~ms}$ of the delay period. On the other hand, in the conventional memory saccade task, the same neuron showed no firing modulation during the delay period, but exhibited a weak transient activity just after saccades (Fig. 4, bottom).

Figure $5 A$ illustrates time courses of population activity for 45 neurons that were formally tested for all four mandatory delay intervals; the remaining 21 ramp-up neurons were tested for only three intervals. The data show that preparatory activity preceded self-timed saccades by $400-1000 \mathrm{~ms}$, even in trials with a $2400 \mathrm{~ms}$ mandatory delay interval (blue trace). Neuronal activity peaked just before saccade initiation, and the maximal firing rate was similar across trials (Fig. 5A, right). In fact, the magnitude of peak activity taken from the spike density profile across individual neurons did not differ between the mandatory delay intervals (one-way ANOVA, $p=0.89$ ). In contrast, no preparatory activity was found during the delay period in the conventional memory saccade task (bottom). Figure $5 B$ plots the population activities for the other 12 neurons that exhibited a gradual decrease of activity before self-timed saccades and were examined for all four mandatory delay conditions. These neurons also modulated their activity several hundred milliseconds before self-timed saccades in all delay conditions, even though the firing modulation was in the opposite direction. Thus, the preparatory activity in the cerebellar dentate nucleus was found only during the self-timed task, no matter whether the animals reported subsecond or supra-second intervals.

For most neurons, the activity before self-timed saccades did not show very strong directional modulation. Figure $6 A$ compares the firing modulation for saccades in opposite directions in trials with a $1200 \mathrm{~ms}$ delay interval. Although 63 of 92 individual neurons $(68 \%)$ exhibited a slight but statistically significant directional modulation (unpaired $t$ test, $p<0.05$; Fig. $6 A$, filled symbols and black bars in the histogram), no significant difference was found for the population as a whole (paired $t$ test, $p=0.09$ ). Among these neurons, the majority ( 66 of $92,72 \%$ ) exhibited ramping up of activity before saccades, while the remaining neurons showed ramping down of activity. For both populations, no significant difference in the magnitude of preparatory activity was observed among the different mandatory delay intervals (Fig. 6B; KruskalWallis test, $p=0.84$ and 0.46 ). These properties of neuronal activity were in line with the model of decision making that assumed a climbing of neuronal activity to a certain threshold (Wittmann, 2013; Ratcliff et al., 2016). Thus, the magnitude of the preparatory activity was comparable between trials, requiring the measurement of sub-second and supra-second intervals.

\section{Neuronal correlates of trial-by-trial variation in movement timing}

Previous studies of self-timing demonstrated the causal relationship between the time course of preparatory activity and the timing of decisions (Janssen and Shadlen, 2005; Jazayeri and Shadlen, 2015; Maimon and Assad, 2006; Tanaka, 2007; Merchant et al., 2011; Murakami et al., 2014). To assess the neuronal correlates of trial-by-trial variation in self-timing, the data for neurons with ramping up of activity were divided into six groups according to saccade latencies of individual neurons, and then the population activity was computed for each group (Fig. $7 A$ ). In addition, to reveal differences in the time course of neuronal activity for trials with shorter intervals, the time scale was normalized against the length of the mandatory delay interval (Fig. $7 B$ ). For the short mandatory intervals (400 and $600 \mathrm{~ms}$, top two 
rows), the preparatory activity started just after the cue offset, and the slope of the ramping up of neuronal activity differed depending on saccade latency, resulting in a strong influence of saccade latency on the duration of the prelude activity. In contrast, for the longest mandatory delay interval (2400 ms, bottom row), the population activity did not alter until $1000-$ $1500 \mathrm{~ms}$ after cue offset, and saccade latency appeared to be well correlated with the onset time of the preparatory activity rather than its slope. Thus, both the duration and slope of ramping activity depended strongly on the trial-by-trial variation of saccade latency in trials with sub-second delay intervals, whereas these values remained unchanged for different saccade timing in trials with the longest delay interval. A similar trend was also found for the smaller population of neurons with ramping down of activity (Fig. 8).

To quantitatively verify this impression, we measured the slope of the ramping activity in each condition for the population of neurons. For this analysis, the data of each neuron were divided into 12 groups (twice the group of Figs. 7, 8) according to saccade latency, and the population activity was computed for each group. Thereafter, the slope of preparatory activity was measured by fitting a regression line to the mean firing rates measured during six $50 \mathrm{~ms}$ intervals (see Materials and Methods). Figure 9A shows a sample measurement of slopes for three different latency groups in trials with a 600 ms mandatory delay interval for neurons with ramp-up of activity. When the slope of the regression line was plotted as a function of mean saccade latency for each of the 12 groups (Fig. 9B, pink data points for the $600 \mathrm{~ms}$ condition), the data showed negative correlation, indicating that the earlier saccades accompanied the steeper slopes of preparatory activity. Regression lines for the three mandatory intervals had statistically significant slopes (Pearson's correlation coefficients, $r=-0.83,-0.90$, and -0.94 for 400,600 , and $1200 \mathrm{~ms}$ intervals, respectively; $p<0.001$ for all three intervals), but that for the $2400 \mathrm{~ms}$ interval did not $(r=$ $-0.17, p=0.61$; Fig. $9 B$, blue data points). Figure $9 D$ compares the bootstrap distribution of correlation coefficients (box-whisker plot, 1000 iterations) with values computed from the population data (red symbols), showing that the difference between the short and the longest mandatory delay intervals was consistently observed. Thus, the rate of rise of the ramping up of activity correlated with trial-by-trial saccade timing for all but the longest mandatory de-
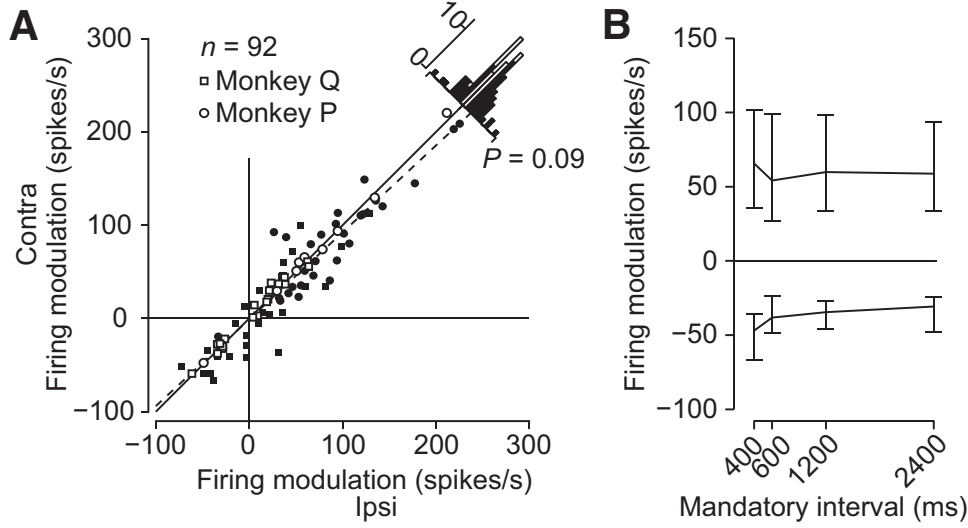

Figure 6. Effects of saccade direction and the mandatory delay interval on the magnitude of neuronal activity before self-timed saccades. $\boldsymbol{A}$, Comparison of presaccadic activity (150-50 ms before saccade initiation, subtracted from the baseline activity) between contraversive and ipsiversive self-timed saccades. Sixty-three (68\%) neurons exhibited a weak but significant directional modulation (unpaired $t$ test, $p<0.05$; filled symbols). There was no directional bias in the population (paired $t$ test, $p=0.09$; regression slope, 0.93 ; mean $\pm S D=39 \pm 66 \mathrm{spikes} / \mathrm{s}$ and $36 \pm 64$ spikes $/ \mathrm{s}$ for ipsiversive and contraversive saccades, respectively). Note that some neurons $(n=12)$ exhibited decreased activity. Two outliers ([-107, -85], [-102,-95]) have been omitted from the scatter plot, but contribute to the histogram. $\boldsymbol{B}$, Median and interquartile range of the population activity for different mandatory delay intervals. Neurons with ramping up of activity $(n=45)$ are plotted separately from those with ramping down of activity $(n=12)$.
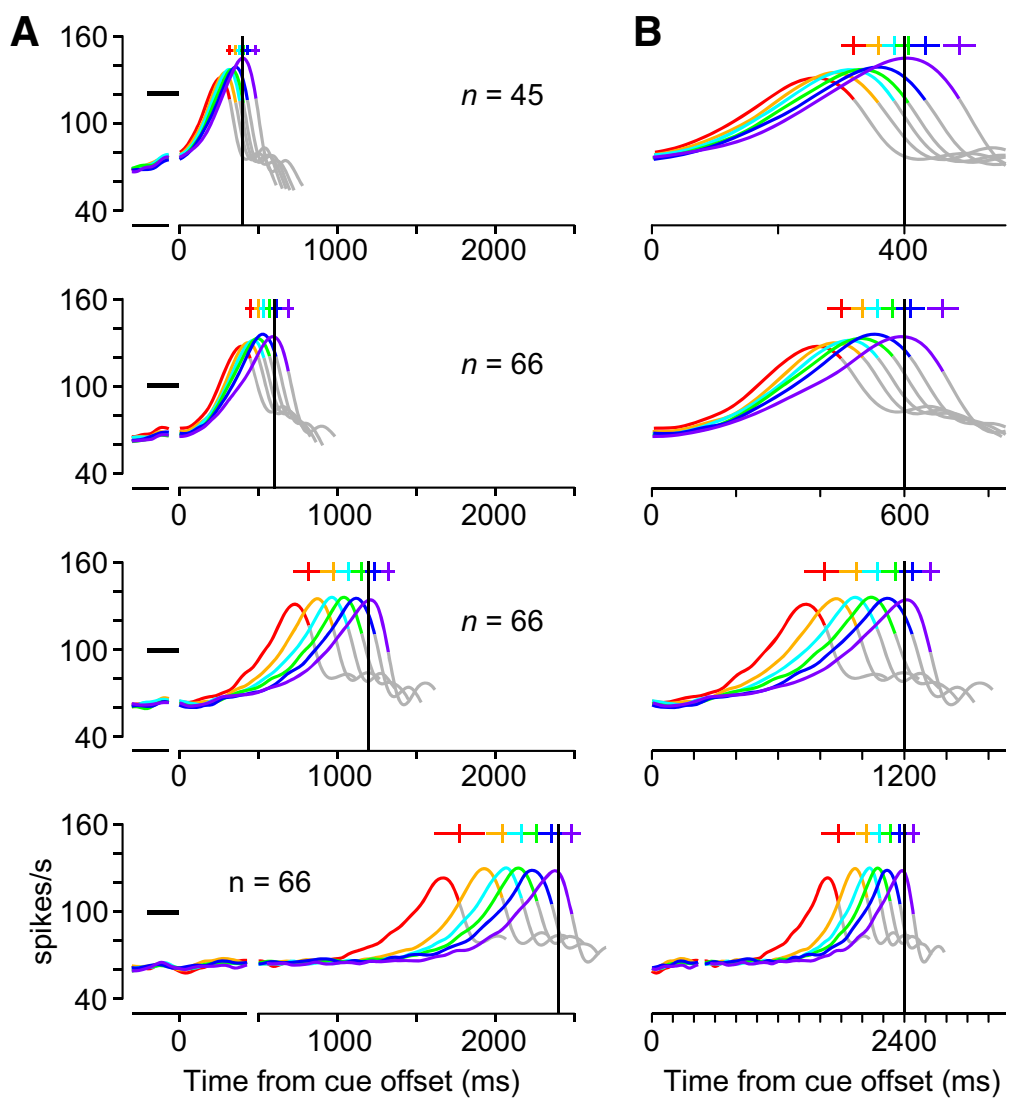

Figure 7. Time courses of population activity of ramp-up neurons for different saccade latencies. $\boldsymbol{A}$, For each neuron and mandatory delay interval, the data were divided into six groups according to saccade latencies. Data were aligned to either the cue offset (left, end of horizontal black bar) or saccade initiation (right) and were then averaged for each of the six groups. For each panel, the right traces are shifted in time so that the times of data alignment are placed at the means of saccade latency relative to the cue offset. Vertical black lines indicate the end of the mandatory delay interval. Crosses in different colors indicate the means and SDs of saccade latency for different groups. Twenty-one of 66 neurons were examined for only three mandatory delay intervals. $\boldsymbol{B}$, The time scale is normalized for the mandatory delay interval to visualize the different time courses of neuronal activity for short intervals. 
A
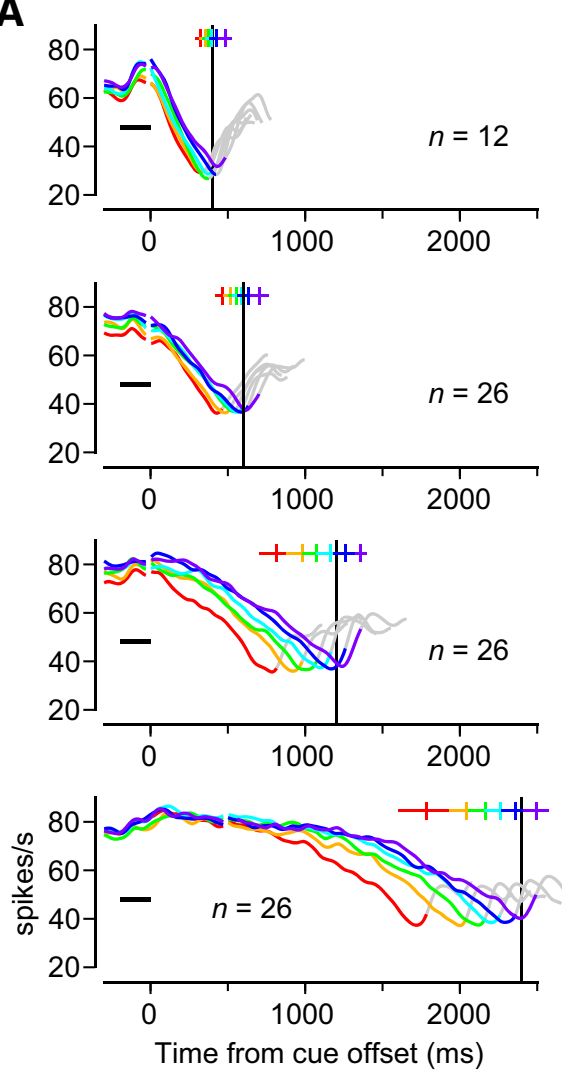

B
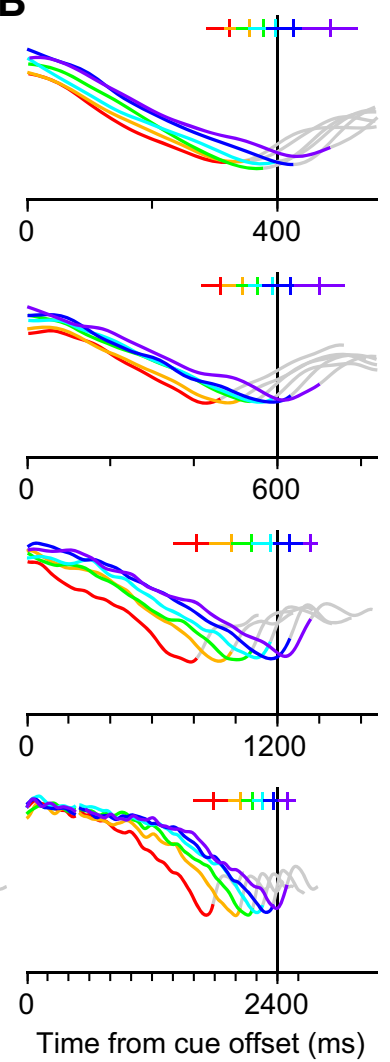

Figure 8. Time courses of population activity of ramp-down neurons for different self-timed saccade latencies. Conventions are the same as in Figure 7.

lay intervals. Similarly, the population activity of ramp-down neurons showed statistically significant slopes for the three shorter intervals (Fig. 9F, red filled circles; $r=0.68,0.74$ and $0.91, p=0.014$, 0.006 , and $<0.001$ for 400,600 , and $1200 \mathrm{~ms}$ intervals, respectively), but not for the $2400 \mathrm{~ms}$ interval $(r=0.39, p=0.21)$.

In contrast, when we looked at the time courses of the population activity, the onset time of preparatory activity differed with different saccade timing only for the longer mandatory intervals (Figs. 7, 8, bottom panels). The different onset times seems to be linked with the saturation of ramp duration; the duration of prelude activity increased in parallel with saccade latency in trials with sub-second delay intervals, but remained constant $(\sim 1 s)$ in trials with supra-second delay interval. Figure $9 C$ plots the onset times of ramping up activity derived from the regression analysis shown in Figure 9A (triangles) for the 12 latency groups in trials with different delay intervals. The data show that while the onset time did not significantly depend on saccadic latency for the shortest $400 \mathrm{~ms}$ delay interval (regression slope, $0.08 ; r=0.25$; $p=0.43)$, the regression slope became steeper for the longer intervals (slopes, $0.25,0.54$, and $0.92 ; r=0.85,0.96$, and 0.99 for 600,1200 , and $2400 \mathrm{~ms}$ delay intervals, respectively; $p<0.001$ for all intervals). The subsequent bootstrap analysis showed that the regression slope for the $2400 \mathrm{~ms}$ delay did not significantly differ from unity, while those for the 400 and $600 \mathrm{~ms}$ delays did not differ from zero (Fig. 9E). For the smaller population of rampdown neurons, the regression slope measured between the rampdown onset and normalized latency steadily increased as the mandatory delay interval increased (Fig. 9G, red circles), and these values significantly correlated only in trials with the $2400 \mathrm{~ms}$ delay interval $(r=0.89, p<0.001)$. We also obtained similar results when the same analyses were performed on the whole population of ramp-up and ramp-down neurons. Again, the slope of ramping activity (practically ramp-up because of the greater number of neurons) significantly correlated with saccade latency for the three shorter intervals $(r=-0.77,-0.80$, and -0.89 for 400,600 , and 1200 ms intervals, respectively; $p<0.01)$, but did not for the longest interval ( $r=0.08, p=0.81)$. In contrast, the time of ramp start did not correlate with saccade latency for the $400 \mathrm{~ms}$ interval $(r=0.30, p=0.35)$, but did for the other intervals $(r=0.80,0.95$ and 0.99 for 600,1200 , and $2400 \mathrm{~ms}$ intervals, respectively; $p<0.01$ ).

To further confirm the validity of quantitative measures for the ramping activity, we also fit the population data of ramp-up neurons with a nonlinear function with the baseline, slope, and onset time using least squares (Materials and Methods; Tanaka, 2007). The results were similar to those summarized in Figures 9, $B$ and $C$. For the analysis of slopes (equivalent to Fig. 9B), the regression coefficients measured for normalized latency were $-0.74,-0.86,-0.96$, and -0.23 for the delay intervals of $400,600,1200$, and $2400 \mathrm{~ms}$, respectively. These values were significantly different from zero for all but the $2400 \mathrm{~ms}$ delay interval $(p<0.01$ for $400-1200 \mathrm{~ms}$ delays, $p=0.48$ for $2400 \mathrm{~ms}$ delay). For the analysis of onset time (equivalent to Fig. $9 C$ ), the regression slopes for normalized latency were 0.22 (Pearson's $r=$ 0.63, $p<0.05), 0.23(r=0.79, p<0.01), 0.46(r=0.97, p<$ $0.001)$, and $0.87(r=0.98, p<0.001)$ for the delay intervals of $400,600,1200$, and $2400 \mathrm{~ms}$, respectively. Together, our data showed that the trial-by-trial variation of saccade latency correlated with the slope of ramping activity when the mandatory delay interval was short, but with the times of activity onset when the mandatory interval was long. These differences might result from the duration limit of ramping activity.

\section{Effects of electrical microstimulation}

To examine the causal relationship between neuronal activity and self-timing, we delivered electrical stimulation $(100 \mu \mathrm{A}, 333 \mathrm{~Hz}$, $200 \mathrm{~ms}$ ) to the recording sites. Figure 10 plots the data from a single experiment, comparing the latencies of ipsiversive saccades between trials with and without stimulation. Electrical stimulation applied 320-520 ms following the cue offset in the self-timed task (600 ms delay) shortened the median saccade latency by 120 ms (Wilcoxon rank sum test, $p<0.001$; Fig. 10A, inverted triangles). On the other hand, in the conventional memory saccade task, the stimulation current delivered during the $600 \mathrm{~ms}$ delay period did not alter saccade latency ( $p=0.14$; Fig. $10 A$, yellow traces), while electrical stimulation at the time of FP offset slightly but significantly shortened the latency in this particular stimulation site (18 ms, $p<0.01$, cyan traces). Similarly, for all other mandatory delay intervals, electrical stimulation in the self-timed task shortened saccade latency by 31-92 ms, whereas the effects in the conventional task were, if any, much smaller (Fig. 10B). As seen in the distributions of self-timed saccade latency (Fig. 10B, top), 
electrical stimulation shifted the entire distribution, and many saccades were generated several hundreds of milliseconds following the stimulation. These results suggest that electrical stimulation did not inject immediate saccade commands, but might facilitate temporal processing in the cerebellum.

Figure $11 \mathrm{~A}$ summarizes the effects of electrical stimulation on self-timed saccade latency for all 19 sites. Stimulation shortened the medians of saccade latency in 68 of 152 cases $(45 \%$, filled symbols, Wilcoxon rank sum test, $p<0.05$ ), including both saccade directions and different mandatory delay intervals. When we compared the changes in saccade latency between conditions (Fig. 11B), the effects on self-timed saccades were significantly greater than those on conventional memory-guided saccades (three-way ANOVA, $F_{(2,422)}=9.7, p<0.001$; multiple comparisons with Tukey's method, $p<0.001)$. On the other hand, there was no significant difference between the two stimulus conditions in the conventional task $(p=0.17)$. Furthermore, we failed to find the main effect of saccade direction $\left(F_{(1,422)}=1.2, p=0.28\right)$. The stimulation effect was largest for the $2400 \mathrm{~ms}$ mandatory interval (one-way ANOVA, $F_{(3,436)}=$ 5.6, $p<0.001)$. Thus, our results show that the signals in the cerebellar dentate nucleus have a causal role in self-timing, while these signals play only a minor role in generating saccades in response to the FP offset in the conventional memoryguided saccade task.

\section{Discussion}

In monkeys performing self-timed saccade task, we found neurons in the cerebellar dentate nucleus with ramping activity that gradually increased or decreased before saccades, rather than those exhibiting temporally tuned activity for certain interval that have been suggested to exist in the cerebellum (Medina and Mauk, 2000) and the cerebral cortex (Mita et al., 2009; Hayashi et al., 2015). A previous study suggested that the ramping activity might directly control self-initiated movement timing, while the temporally tuned signals might serve as inputs to generate the ramping signals (Murakami et al., 2014). Contrary to our expectation, we found that most neurons exhibited a similar time course of activity for different delay intervals (Fig. 12A). Further analysis revealed that the trial-by-trial variation of saccade timing correlated with the slope of ramping up of activity for the delay of 400-1200 ms, but with the start of activity for the delay of $2400 \mathrm{~ms}$ (Fig. 9). Because electrical stimulation advanced self-initiated saccades in both directions, the preparatory signals in the dentate nucleus may have a causal role in self-timing.
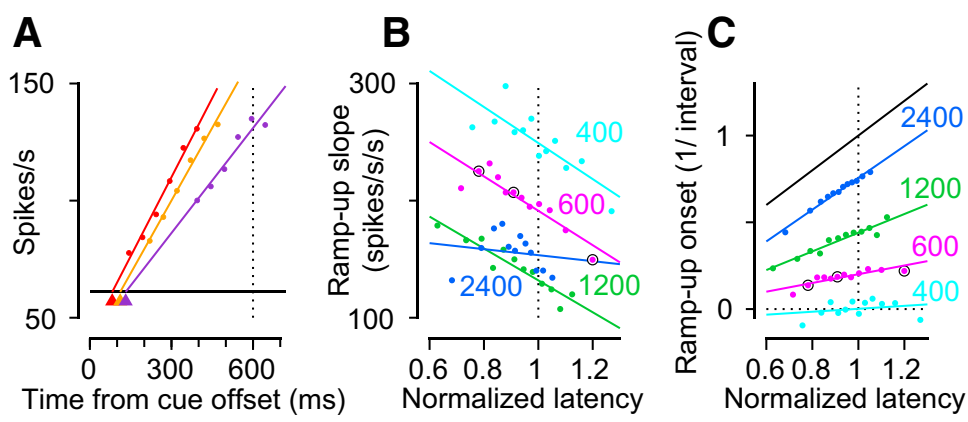

Figure 9. Correlation between the time course of ramping activity and self-timing. $\boldsymbol{A}$, Sample regression lines for three sets of six data points (dots) of the population activity of ramp-up neurons. Data for the $600 \mathrm{~ms}$ mandatory delay interval were divided into 2 groups according to saccade latency, but only the data for the 2nd (red), 6th (orange), and 12th (purple) groups are displayed. (black horizontal line). $\boldsymbol{B}$, Correlation between the rate of rise of neuronal activity and saccade latency. The regression slopes measured as in $\boldsymbol{A}$ are plotted against the normalized saccade latency. Data points with black circles indicate the data shown in $\boldsymbol{A}$. (hote that the regression line for the $2400 \mathrm{~ms}$ delay (blue) is almost parallel to the black solid line with a unity slope, while 政 $\mathbf{G}$, Correlation coefficients and regression slopes for ramp-down neurons. In $\mathbf{G}$, the whiskers are truncated for the shorter delay intervals ([-3.7, 2.8], [-2.3, 2.0], and [-2.1, 2.1] for 400,600, and $1200 \mathrm{~ms}$, respectively).

\section{Cerebellar involvement in fine adjustment of self-timing}

Neurons in the cerebellar dentate nucleus did not modulate their firing rate during the initial half of the $2400 \mathrm{~ms}$ mandatory delay period (Fig. 7A); therefore, they are unlikely to participate in keeping track of the supra-second interval. In contrast, functional imaging studies have detected increased activity in the basal ganglia during tasks requiring supra-second timing (Rao et al., 2001; Nenadic et al., 2003; Harrington et al., 2004). We therefore hypothesized that the corticobasal ganglia pathways may monitor passage of time in the range of seconds, while the cerebellum may participate only in the last part of the delay period, playing a role in the fine adjustment of movement timing (Fig. $12 B)$.

Several previous observations might be relevant to our hypothesis. First, besides the slow multisynaptic transcortical pathways, the basal ganglia and cerebellum communicate with each 


\section{A Self-timed}

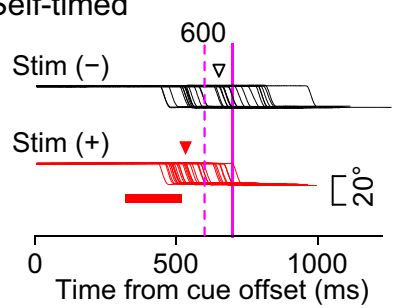

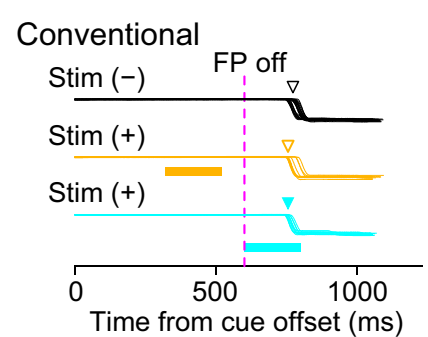

B Self-timed

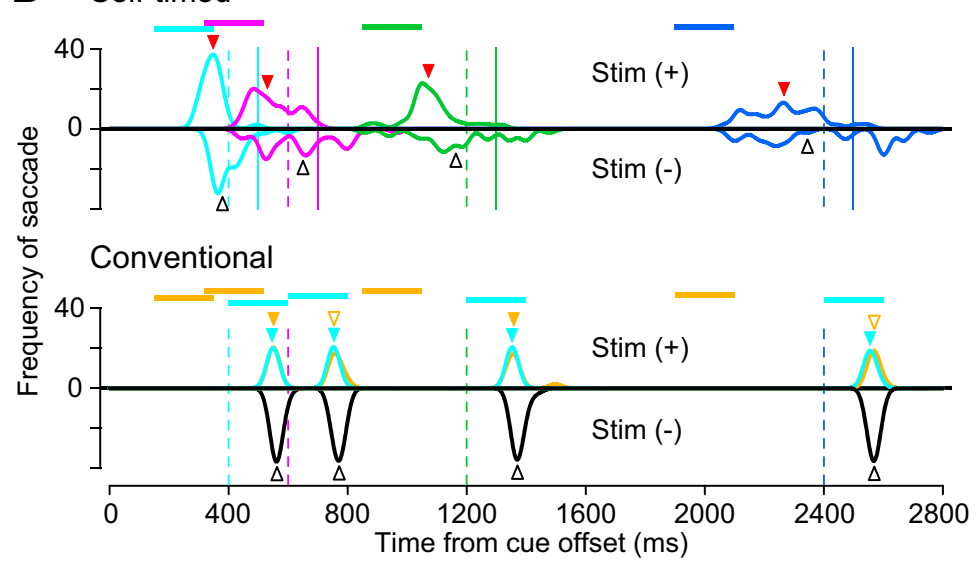

Figure 10. Effects of electrical microstimulation on saccade latency. $A$, Eye position traces in trials with and without electrical stimulation. Left, Vertical solid and dashed lines indicate the times of audiovisual feedback and the termination of the $600 \mathrm{~ms}$ mandatory delay interval, respectively. Right, The vertical dashed line indicates the FP offset in the conventional memory saccade task. Only ipsiversive saccade trials with a $600 \mathrm{~ms}$ mandatory delay interval are shown. Bars in different colors indicate the timing of electrical stimulation (100 $\mu \mathrm{A}, 200 \mathrm{~ms}$ in duration). Inverted triangles indicate the median latency. Filled triangles indicate the data with a significant stimulation effect (Wilcoxon rank sum test, $p<0.05$ ). $\boldsymbol{B}$, Distribution of ipsiversive saccade latency with and without electrical stimulation delivered to the same site as in $\boldsymbol{A}$. For self-timed saccades (top), different colors represent different mandatory delay intervals. The timing of the feedback signal is indicated by vertical solid lines, while the end of the mandatory interval is shown by vertical dashed lines. For the conventional memory saccade trials (bottom), different colors indicate different stimulation timings, whereas the distributions for the two timings almost overlap. Vertical dashed lines denote the FP offset that occurred either $400,600,1200$, or 2400 ms following the cue offset.

other through subcortical pathways (Hoshi et al., 2005; Bostan et al., 2013). Such a direct link suggests that these structures may operate synergistically to generate movements (McCairn et al., 2013; Chen et al., 2014). Second, the midbrain dopaminergic neurons send axons to the cerebellum (Ikai et al., 1992) and the inferior olive (Toonen et al., 1998), indicating that there could be interaction between learning in the basal ganglia and the cerebellum (Ohmae and Medina, 2015). Finally, the cerebellumrecipient thalamic neurons in rodents send axons to the deeper layers of the motor cortex, while the basal ganglia-recipient thalamic neurons project to the superficial layers (Kuramoto et al., 2009). The different inputs suggest dominant roles in the generation and preparation of movements for the cerebellum and basal ganglia, respectively.

The sequential processing of temporal information from the basal ganglia to the cerebellum might be advantageous for rapid changes in behavioral requirements. In our behavioral paradigm, animals needed to switch saccade timing as the mandatory delay interval was altered every 10 trials (Fig. $1 C$ ). The basal ganglia are relevant to a rapid change in behavioral strategy (Frank et al., 2007; Isoda and Hikosaka, 2007; Yoshida and Tanaka, 2009; Sheth et al., 2011), and, indeed, subjects with Parkinson's disease have a difficulty in updating temporal information in the duration reproduction task (Malapani et al., 1998; Koch et al., 2008; Allman and Meck, 2012). In contrast, although the cerebellum is essential for motor learning, cerebellar adaptation to changes in the environment is generally slow and takes from several tens to hundreds of trials (Hopp and Fuchs, 2004; Bastian, 2008; but see Yang and Lisberger, 2014). In our experimental conditions, the basal ganglia might flexibly alter neuronal activity to measure the interval timing depending on the behavioral goal, while the cerebellum is active only during the last part of the delay period to maintain temporally accurate movements. The cerebellar roles in the fine adjustment of timing may not be limited to movements, but also be shared with perception (Roth et al., 2013).

We also found that the trial-by-trial variation of saccade timing negatively correlated with the slope of the ramping activity for the mandatory delays of 400-1200 ms, but not for the delay of $2400 \mathrm{~ms}$ (Figs. 9D, F). This might be because the relative contribution of the cerebellum to self-timing was greater for the shorter intervals than for the longest interval (Fig. 12B); the variation of timing for the shorter delays may depend on neuronal activity in the cerebellum, whereas that for the $2400 \mathrm{~ms}$ delay might be mostly attributed to neuronal activity outside of the cerebellum. The time of activity initiation in the cerebellum might be determined by signals in the corticobasal ganglia pathways when the mandatory delay is long. Thus, our data suggest that the relative contribution of the cerebellum is greater for sub-second than suprasecond timing. These differences, however, do not necessarily indicate smaller neuronal modulation in the cerebellum for supra-second timing, as the magnitude of firing modulation was comparable across the intervals (Fig. 6B).

The causal relationship between neuronal activity in the cerebellum and self-timing were supported by the results of electrical stimulation. However, the greater stimulation effects on saccade timing in trials with longer delay intervals seemingly contradict our hypothesis (Fig. 11B). The different stimulation effects might be attributed to the following two reasons. First, the slope of the ramping up of activity was consistently shallower for the trials with longer delay intervals (Fig. 9B). Assuming that the slope of neuronal activity reflected the speed of subjective passage of time (Wittmann, 2013), the fixed change in neuronal activity by electrical stimulation would have more impact on self-timing for longer intervals. Second, the level of neuronal activity at the time of electrical stimulation might be different depending on the length of the delay period. If neuronal activity reached a threshold for triggering saccades in the middle of the $200 \mathrm{~ms}$ stimulation train, the later part of the stimulation could not contribute to changes in saccade timing. In fact, for the experiment shown in Figure $10 B$, saccades were generated before 
the termination of electrical stimulation in approximately half of the trials with a 400 ms delay interval.

\section{Possible neuronal mechanism and relevance to previous studies}

How are the preparatory signals in the cerebellum generated and used for self-timing? Previous analyses of eye blink conditioning might provide some insight. In this system, the model predicts that sustained inputs to the cerebellum are necessary to generate temporally accurate movements (Mauk and Buonomano, 2004). In trace eye blink conditioning, sustained activity in the cerebral cortex appears to play a role in bridging the temporal gap between the stimulus and response (Kalmbach et al., 2010). In our selftimed saccade paradigm, only the FP could provide a sensory signal during the monitoring of elapsed time. However, because the time between the FP onset and the visual cue varied from trial to trial, the signals derived from the FP would be insufficient to measure the time following the cue offset. Similarly, to trace eye blink conditioning, the corticobasal ganglia network might provide sustained signals to the cerebellum to generate the ramping up of activity in the nucleus.

The time courses of neuronal activity shown in Figure 7 were in good agreement with the notion that self-initiated saccades were generated when neuronal activity in the cerebellum reached a certain threshold. However, because electrical stimulation altered the latency of self-initiated saccades in both directions but failed to alter reactive saccades, the signals in the dentate nucleus were unlikely to generate an immediate motor drive. Instead, the stimulation effects persisted even when stimulation pulses terminated just before self-timed saccades (Fig. $10 B)$, suggesting that the signals in the cerebellum might be further integrated in the downstream pathways generating saccades. The signals injected by unilateral stimulation might propagate to both sides of the brain through the crossed connections and modulate the temporal processing for selfinitiated movements. We did not deliver electrical stimulation at very early timing in the delay period because neurons at the recording sites did not modulate firing rate at that period. Nonetheless, we speculate that such stimulation would be less effective, because stimulation to the supplementary eye field at a very early delay period showed only a slight effect (Kunimatsu and Tanaka, 2012).

In summary, we found that neurons in the cerebellar dentate nucleus participated in self-timing both in the sub-second and supra-second ranges. Because of the $\sim 1.5 \mathrm{~s}$ temporal limit of eye blink conditioning, the cerebellum has been thought to play a role in sub-second timing (Medina and Mauk, 2000; Mauk and Buonomano, 2004). Indeed, we found that neuronal activity reand supra-second ranges.
A
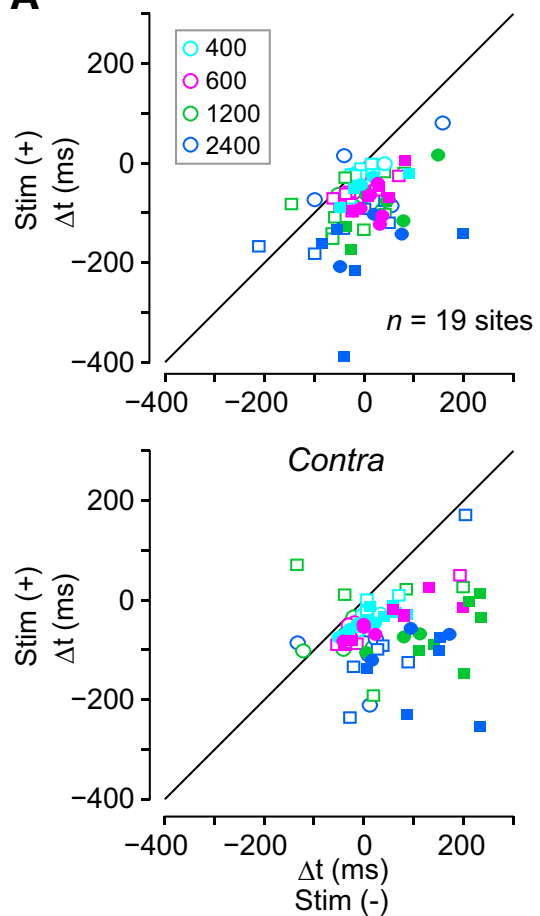

B Ipsi
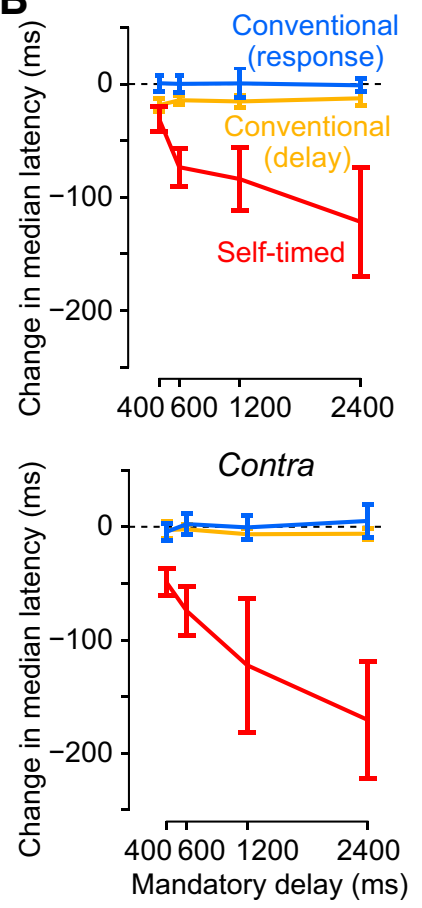

Figure 11. Quantitative summary of the stimulation effects on saccade latency. $\boldsymbol{A}$, Comparison of median saccade latencies relative to the mandatory delay interval between the trials with and without electrical stimulation. Different colors represent different delay intervals. Filled symbols indicate data with a significant difference (Wilcoxon rank sum test, $p<0.05$ ). $\boldsymbol{B}$, The means and $95 \%$ confidence intervals of changes in median latencies during stimulation of 19 sites. Note that the stimulation effects

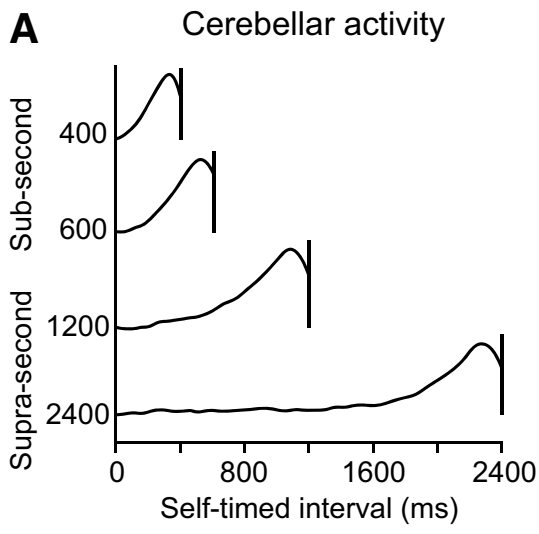

B New hypothesis

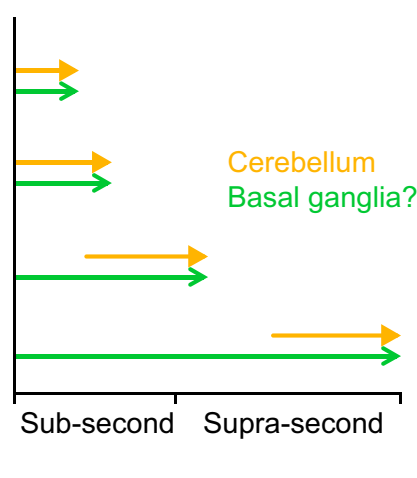

Figure 12. Possible role of the cerebellum in the fine adjustment of self-timing. $\boldsymbol{A}$, Time courses of population activity for different mandatory delay intervals, replotted from Figure 5. B, Possible sequence of neuronal activity with time in the sub-second

corded from the cerebellar dentate nucleus never persisted for $>1$ $\mathrm{s}$, while these neurons exhibited a sizeable preparatory activity for both sub-second and supra-second intervals. The sustained activity during timing tasks in the basal ganglia (Lee and Assad, 2003; Turner and Anderson, 2005), the thalamus (Tanaka, 2007), and the cerebral cortex (Leon and Shadlen, 2003; Merchant et al., 2011; Jazayeri and Shadlen, 2015) might regulate the times of preparatory signals in the cerebellum. Neuronal activity in these structures needs to be elucidated in future studies.

\section{References}

Allman MJ, Meck WH (2012) Pathophysiological distortions in time perception and timed performance. Brain 135:656-677. CrossRef Medline 
Ashmore RC, Sommer MA (2013) Delay activity of saccade-related neurons in the caudal dentate nucleus of the macaque cerebellum. J Neurophysiol 109:2129-2144. CrossRef Medline

Bares M, Lungu O, Liu T, Waechter T, Gomez CM, Ashe J (2007) Impaired predictive motor timing in patients with cerebellar disorders. Exp Brain Res 180:355-365. CrossRef Medline

Bastian AJ (2008) Understanding sensorimotor adaptation and learning for rehabilitation. Curr Opin Neurol 21:628-633. CrossRef Medline

Bostan AC, Dum RP, Strick PL (2013) Cerebellar networks with the cerebral cortex and basal ganglia. Trends Cogn Sci 17:241-254. CrossRef Medline

Buhusi CV, Meck WH (2005) What makes us tick? Functional and neural mechanisms of interval timing. Nat Rev Neurosci 6:755-765. CrossRef Medline

Chen CH, Fremont R, Arteaga-Bracho EE, Khodakhah K (2014) Short latency cerebellar modulation of the basal ganglia. Nat Neurosci 17:17671775. CrossRef Medline

Dum RP, Strick PL (2003) An unfolded map of the cerebellar dentate nucleus and its projections to the cerebral cortex. J Neurophysiol 89:634639. Medline

Frank MJ, Samanta J, Moustafa AA, Sherman SJ (2007) Hold your horses: impulsivity, deep brain stimulation, and medication in parkinsonism. Science 318:1309-1312. CrossRef Medline

Harrington DL, Boyd LA, Mayer AR, Sheltraw DM, Lee RR, Huang M, Rao SM (2004) Neural representation of interval encoding and decision making. Brain Res Cogn Brain Res 21:193-205. CrossRef Medline

Hayashi MJ, Ditye T, Harada T, Hashiguchi M, Sadato N, Carlson S, Walsh V, Kanai R (2015) Time adaptation shows duration selectivity in the human parietal cortex. PLoS Biol 13:e1002262. CrossRef Medline

Hikosaka O, Wurtz RH (1983) Visual and oculomotor functions of monkey substantia nigra pars reticulata. III. Memory-contingent visual and saccade responses. J Neurophysiol 49:1268-1284. Medline

Hopp JJ, Fuchs AF (2004) The characteristics and neuronal substrate of saccadic eye movement plasticity. Prog Neurobiol 72:27-53. CrossRef Medline

Hoshi E, Tremblay L, Féger J, Carras PL, Strick PL (2005) The cerebellum communicates with the basal ganglia. Nat Neurosci 8:1491-1493. CrossRef Medline

Ikai Y, Takada M, Shinonaga Y, Mizuno N (1992) Dopaminergic and nondopaminergic neurons in the ventral tegmental area of the rat project, respectively, to the cerebellar cortex and deep cerebellar nuclei. Neuroscience 51:719-728. CrossRef Medline

Ikeda A, Shibasaki H, Nagamine T, Terada K, Kaji R, Fukuyama H, Kimura J (1994) Dissociation between contingent negative variation and Bereitschaftspotential in a patient with cerebellar efferent lesion. Electroencephalogr Clin Neurophysiol 90:359-364. CrossRef Medline

Isoda M, Hikosaka O (2007) Switching from automatic to controlled action by monkey medial frontal cortex. Nat Neurosci 10:240-248. CrossRef Medline

Ivry RB, Keele SW (1989) Timing functions of the cerebellum. J Cogn Neurosci 1:136-152. CrossRef Medline

Ivry RB, Spencer RM (2004) The neural representation of time. Curr Opin Neurobiol 14:225-232. CrossRef Medline

Janssen P, Shadlen MN (2005) A representation of the hazard rate of elapsed time in macaque area LIP. Nat Neurosci 8:234-241. CrossRef Medline

Jazayeri M, Shadlen MN (2015) A neural mechanism for sensing and reproducing a time interval. Curr Biol 25:2599-2609. CrossRef Medline

Kalmbach BE, Ohyama T, Mauk MD (2010) Temporal patterns of inputs to cerebellum necessary and sufficient for trace eyelid conditioning. J Neurophysiol 104:627-640. CrossRef Medline

Koch G, Costa A, Brusa L, Peppe A, Gatto I, Torriero S, Gerfo EL, Salerno S, Oliveri M, Carlesimo GA, Caltagirone C (2008) Impaired reproduction of second but not millisecond time intervals in Parkinson's disease. Neuropsychologia 46:1305-1313. CrossRef Medline

Kunimatsu J, Tanaka M (2012) Alteration of the timing of self-initiated but not reactive saccades by electrical stimulation in the supplementary eye field. Eur J Neurosci 36:3258-3268. CrossRef Medline

Kuramoto E, Furuta T, Nakamura KC, Unzai T, Hioki H, Kaneko T (2009) Two types of thalamocortical projections from the motor thalamic nuclei of the rat: a single neuron-tracing study using viral vectors. Cereb Cortex 19:2065-2077. CrossRef Medline

Lee IH, Assad JA (2003) Putaminal activity for simple reactions or selftimed movements. J Neurophysiol 89:2528-2537. CrossRef Medline
Leon MI, Shadlen MN (2003) Representation of time by neurons in the posterior parietal cortex of the macaque. Neuron 38:317-327. CrossRef Medline

Lewis PA, Miall RC (2003a) Distinct systems for automatic and cognitively controlled time measurement: evidence from neuroimaging. Curr Opin Neurobiol 13:250-255. CrossRef Medline

Lewis PA, Miall RC (2003b) Brain activation patterns during measurement of sub- and supra-second intervals. Neuropsychologia 41:1583-1592. CrossRef Medline

Maimon G, Assad JA (2006) Parietal area 5 and the initiation of self-timed movements versus simple reactions. J Neurosci 26:2487-2498. CrossRef Medline

Malapani C, Rakitin B, Levy R, Meck WH, Deweer B, Dubois B, Gibbon J (1998) Coupled temporal memories in Parkinson's disease: a dopaminerelated dysfunction. J Cogn Neurosci 10:316-331. CrossRef Medline

Mauk MD, Buonomano DV (2004) The neural basis of temporal processing. Annu Rev Neurosci 27:307-340. CrossRef Medline

McCairn KW, Iriki A, Isoda M (2013) Global dysrhythmia of cerebro-basal ganglia-cerebellar networks underlies motor tics following striatal disinhibition. J Neurosci 33:697-708. CrossRef Medline

Medina JF, Mauk MD (2000) Computer simulation of cerebellar information processing. Nat Neurosci 3:1205-1211. CrossRef Medline

Merchant H, Zarco W, Pérez O, Prado L, Bartolo R (2011) Measuring time with different neural chronometers during a synchronization-continuation task. Proc Natl Acad Sci U S A 108:19784-19789. CrossRef Medline

Merchant H, Harrington DL, Meck WH (2013) Neural basis of the perception and estimation of time. Annu Rev Neurosci 36:313-336. CrossRef Medline

Mita A, Mushiake H, Shima K, Matsuzaka Y, Tanji J (2009) Interval time coding by neurons in the presupplementary and supplementary motor areas. Nat Neurosci 12:502-507. CrossRef Medline

Murakami M, Vicente MI, Costa GM, Mainen ZF (2014) Neural antecedents of self-initiated actions in secondary motor cortex. Nat Neurosci 17:1574-1582. CrossRef Medline

Nenadic I, Gaser C, Volz HP, Rammsayer T, Häger F, Sauer H (2003) Processing of temporal information and the basal ganglia: new evidence from fMRI. Exp Brain Res 148:238-246. CrossRef Medline

Ohmae S, Medina JF (2015) Climbing fibers encode a temporal-difference prediction error during cerebellar learning in mice. Nat Neurosci 18 : 1798-1803. CrossRef Medline

Ohmae S, Uematsu A, Tanaka M (2013) Temporally specific sensory signals for the detection of stimulus omission in the primate deep cerebellar nuclei. J Neurosci 33:15432-15441. CrossRef Medline

O'Reilly JX, Mesulam MM, Nobre AC (2008) The cerebellum predicts the timing of perceptual events. J Neurosci 28:2252-2260. CrossRef Medline

Rao SM, Mayer AR, Harrington DL (2001) The evolution of brain activation during temporal processing. Nat Neurosci 4:317-323. CrossRef Medline

Ratcliff R, Smith PL, Brown SD, McKoon G (2016) Diffusion decision model: current issues and history. Trends Cogn Sci 20:260-281. CrossRef Medline

Robinson FR, Straube A, Fuchs AF (1993) Role of the caudal fastigial nucleus in saccade generation. II. Effects of muscimol inactivation. J Neurophysiol 70:1741-1758. Medline

Roth MJ, Synofzik M, Lindner A (2013) The cerebellum optimizes perceptual predictions about external sensory events. Curr Biol 23:930-935. CrossRef Medline

Sasaki K, Gemba H, Hashimoto S, Mizuno N (1979) Influences of cerebellar hemispherectomy on slow potentials in the motor cortex preceding selfpaced hand movements in the monkey. Neurosci Lett 15:23-28. CrossRef Medline

Schaal S, Sternad D, Osu R, Kawato M (2004) Rhythmic arm movement is not discrete. Nat Neurosci 7:1136-1143. CrossRef Medline

Sheth SA, Abuelem T, Gale JT, Eskandar EN (2011) Basal ganglia neurons dynamically facilitate exploration during associative learning. J Neurosci 31: 4878-4885. CrossRef Medline

Spencer RM, Zelaznik HN, Diedrichsen J, Ivry RB (2003) Disrupted timing of discontinuous but not continuous movements by cerebellar lesions. Science 300:1437-1439. CrossRef Medline

Strick PL, Dum RP, Fiez JA (2009) Cerebellum and nonmotor function. Annu Rev Neurosci 32:413-434. CrossRef Medline 
Tanaka M (2005) Involvement of the central thalamus in the control of smooth pursuit eye movements. J Neurosci 25:5866-5876. CrossRef Medline

Tanaka M (2006) Inactivation of the central thalamus delays self-timed saccades. Nat Neurosci 9:20-22. CrossRef Medline

Tanaka M (2007) Cognitive signals in the primate motor thalamus predict saccade timing. J Neurosci 27:12109-12118. CrossRef Medline

Thach WT, Goodkin HP, Keating JG (1992) The cerebellum and the adaptive coordination of movement. Annu Rev Neurosci 15:403-442. Medline

Thaut MH, Demartin M, Sanes JN (2008) Brain networks for integrative rhythm formation. P:loS one 3:e2312. CrossRef

Thier P, Dicke PW, Haas R, Barash S (2000) Encoding of movement time by populations of cerebellar Purkinje cells. Nature 405:72-76. CrossRef Medline

Toonen M, van Dijken H, Holstege JC, Ruigrok TJ, Koekkoek SK, Hawkins RK, Teune TM, vd Burg J, De Zeeuw CI (1998) Light microscopic and ultrastructural investigation of the dopaminergic innervation of the ven- trolateral outgrowth of the rat inferior olive. Brain Res 802:267-273. CrossRef Medline

Turner RS, Anderson ME (2005) Context-dependent modulation of movementrelated discharge in the primate globus pallidus. J Neurosci 25:2965-2976. CrossRef Medline

Vilis T, Hore J (1980) Central neural mechanisms contributing to cerebellar tremor produced by limb perturbations. J Neurophysiol 43:279-291. Medline

Wittmann M (2013) The inner sense of time: how the brain creates a representation of duration. Nat Rev Neurosci 14:217-223. CrossRef Medline

Xu D, Liu T, Ashe J, Bushara KO (2006) Role of the olivo-cerebellar system in timing. J Neurosci 26:5990-5995. CrossRef Medline

Yang Y, Lisberger SG (2014) Purkinje-cell plasticity and cerebellar motor learning are graded by complex-spike duration. Nature 510:529-532. CrossRef Medline

Yoshida A, Tanaka M (2009) Enhanced modulation of neuronal activity during antisaccades in the primate globus pallidus. Cereb Cortex 19:206217. CrossRef Medline 